\title{
Mediación en conflictos armados. La experiencia de la Asociación de Trabajadores Campesinos del Carare (ATCC) ${ }^{1}$
}

\author{
Mediation in armed conflicts. The experience of the \\ association of rural workers of carare (ATCC)
}

\author{
Mediaçaõ de conflitos armados. A experiência da Associação \\ de Trabalhadores do Campo de Carare (ATCC)
}

Recepción: 19/01/2020

Evaluación: 16/05/2020

Aceptación: 28/05/2020

Artículo de Investigación - Revisión

https://doi.org/10.19053/01227238.11919

Esperanza Hernández Delgado²

Universidad de La Salle, Colombia

https://orcid.org/0000-0001-9816-4086

\section{RESUMEN}

Este artículo, producto de investigación para la paz $z^{3}$, tiene por objeto analizar desde la teoría de los Estudios de $\mathrm{Paz}^{4}$ la experiencia de mediación de la Asociación de Trabajadores Campesinos del Carare (ATCC) en el conflicto armado interno colombiano. Su originalidad consiste en abordar una mediación realizada por una comunidad campesina involucrada en este conflicto, dada su afectación por el mismo; y recoger un modelo genuino de mediación generado por la ATCC. El método aplicado fue el de la Investigación Acción Participante (IAP) $)^{5}$ y se soportó en

1 Este artículo es fruto de investigación para la paz y está centrado en experiencias de mediación en el conflicto armado colombiano. La investigación se llevó a cabo entre 2010 y 2012, en desarrollo de una alianza entre la Universidad Autónoma de Bucaramanga (UNAB)-Instituto de Estudios Políticos, la Unión Europea y Pensamiento y Acción Social (PAS), con el auspicio de la Unión Europea.

$2 \mathrm{PhD}$ en Paz, Conflictos y Democracias de la Universidad de Granada, España, y magíster en Estudios Políticos de la Pontificia Universidad Javeriana. Académica e investigadora para la paz. Actualmente está vinculada a la Universidad de La Salle en el Doctorado en Educación y Sociedad, correo electronico: eehernandez@unisalle.edu.co.

3 La investigación para la paz es una modalidad de investigación propia de los Estudios de Paz. Puede ser comprendida como la indagación en el pasado y el presente para conocer lo que se requiere para construir paz. Véase a Johan Galtung, Investigaciones teóricas. Sociedad y culturas contemporáneas (Madrid: Tecnos, 1995), 347.

4 Los Estudios de Paz surgieron en 1945, en tiempos de post Segunda Guerra Mundial. Representan un ámbito de conocimiento centrado en la paz y generado a partir de categorías analíticas, enfoques y modalidades de investigación que lo soportan y le dan contenidos, como la historia de la paz, la investigación para la paz, la educación para la paz, la cultura de paz, y la construcción de la paz. Véase a Francisco A. Muñoz et al., Investigación de la Paz y los Derechos Humanos desde Andalucía (Granada: Universidad de Granada, 2005), 29.

5 La Investigación Acción Participante (IAP) encontró su origen a mediados de la década de los cuarenta, en la búsqueda de enfoques alternativos de investigación y trabajo comunitario que lograran un mayor impacto en términos de transformación social. Hizo presencia en Colombia a partir de 1977. Ha sido considerada como metodología de investigación y aprendizaje y se caracteriza por estar ligada al cambio social. Devuelve o fortalece la condición de sujetos sociales a quienes participan en ella, busca la unidad entre la teoría y la práctica, estimula el desarrollo del pensamiento creativo mediante la aplicación de principios como "aprender haciendo", articula saberes académicos con otros saberes, y plantea que la generación de conocimiento no solo es posible a través de expertos sino como producto de saberes integrados de investigadores e investigados. Véase a María Cristina Salazar, ed., $L a$ investigación-acción participativa. Inicios y desarrollos (Santafé de Bogotá, D. C.: Editora Géminis, 1992), 137. 
la estrategia de un trabajo de campo que permitió una observación in situ y entrevistas semiestructuradas a actores relevantes. Conclusión: la ATCC enseña un método innovador de mediación comunitaria, la importancia de mediadores internos e involucrados y los alcances de esta mediación en los conflictos armados internos.

Palabras clave: mediación comunitaria; conflicto armado interno; paces; Carare, Colombia.

\section{ABSTRACT}

This article is a research product for peace, it aims at analyzing from the theory of Peace Studies the mediation experience of the Carare Peasant Workers Association (ATCC from Spanish version) in the Colombian internal armed conflict. Its novelty rests in approaching a mediation carried out by a peasant community, involved in this conflict, given its involvement by it; and collect a genuine mediation model generated by the ATCC. The Participant Action Research (PAR) was the method implemented and it was supported by a fieldwork strategy that allowed for in situ observation and semi-structured interviews with relevant participants. Conclusion ATCC teaches an innovative method of community mediation, the importance of internal and involved mediators and the scope of this mediation in internal armed conflicts.

Key words: Community mediation; internal armed conflict; peace; Carare; Colombia.

\section{RESUMO}

Este artigo, produto de pesquisa para a paz, tem por objeto analisar a teoria dos Estudos da Paz à experiência de mediação da Associação de Trabalhadores do Campo de Carare (ATCC) no conflito armado interno da Colômbia. Sua originalidade consiste em abordar uma mediação realizada por uma comunidade campesina, envolvida neste conflito, considerando o fato de ser afetada pelo mesmo; e recorrer a um modelo genuíno de mediação gerado pela ATCC. O método aplicado foi a Pesquisa da Ação
Participante, e se apoiou na estratégia de um trabalho de campo que permitiu uma observação in situ e entrevistas semiestruturadas a atores relevantes. Conclusão: a ATCC ensina um método inovador de mediação comunitária, a importância de mediadores internos e envolvidos e a abrangência desta mediação nos conflitos armados internos.

Palavras-chave: mediação comunitária; conflito armado interno; paz; Carare; Colômbia.

\section{INTRODUCCIÓN}

En forma tradicional, Colombia ha sido reconocida por sus históricas y recurrentes violencias, desde las estructurales de la exclusión y la marginalidad, hasta la directa del conflicto interno armado ${ }^{6}$. No obstante, hallazgos de investigación para la paz evidencian que, en los últimos cincuenta años, este país ha registrado también un universo significativo y creciente de escenarios de construcción de $\mathrm{paz}^{7}$, dentro del cual

\footnotetext{
6 Gonzalo Sánchez y Ricardo Peñaranda, comps., Pasado y presente de la Violencia en Colombia (Bogotá: Cerec, 1986).

7 Esperanza Hernández Delgado, Resistencia civil, artesana de paz. Experiencias indígenas, afrodescendientes y campesinas (Bogotá:
} 
se identifican experiencias de resistencia noviolenta ${ }^{8}$, mediaciones en el conflicto interno armado, procesos de paz $^{9}$, y un activo y persistente movimiento por la paz $^{10}$. Sus logros son palpables y perfectibles, al igual que las paces que construyen.

En diversos lugares de Colombia, al mismo tiempo que se dinamiza y agudiza el conflicto armado interno, los sectores más impactados ${ }^{11}$ han desarrollado métodos y estrategias para contactar, dialogar y facilitar acuerdos con los actores armados. Estas intervenciones han sido reconocidas por ellos mismos como prácticas de mediación y, en términos de Lederach, estos mediadores podrían calificarse como "Incider Partial"12, o mediadores involucrados en el conflicto o de confianza, por su condición de afectados por el mismo. El objetivo de estas intervenciones comunitarias ha estado relacionado con la búsqueda de alternativas que permitan proteger mínimos vitales violentados o amenazados en el marco del conflicto en mención: la vida, el territorio, las culturas y la autonomía o autodeterminación ${ }^{13}$.

Algunas de estas experiencias de mediación comunitaria han alcanzado una larga duración, todas otorgan significados a la mediación que practican, sus métodos y estrategias son propios y muy creativos, y sus alcances visibles y significativos. Además, surgen de actores sociales que han ejercido la resistencia noviolenta, pero al mismo tiempo han estado abiertos a la solución dialogada de los conflictos que los afectan ${ }^{14}$. En este contexto se ubica la experiencia de mediación de la ATCC.

Estas realidades de Colombia permiten afirmar que los colombianos no están atados irremediablemente a las violencias. En este país, una paz empoderada y perfectible se construye en medio y a pesar de las violencias. También evidencian las posibilidades del diálogo y los alcances de los métodos noviolentos en la resolución y transformación de los conflictos armados.

\section{Sobre la mediación}

La mediación ha estado presente a lo largo de la historia. Dan cuenta de ello los "consejos del pueblo" en Sri Lanka, en el año 425 a. C., integrados por los más ancianos, quienes escuchaban las quejas y resolvían conflictos entre vecinos ${ }^{15} ; \mathrm{y}$

Editorial Pontificia Universidad Javeriana, 2004), 316-326.

8 Cécile Mouly y María Belén Garrido, "No a la guerra. Resistencia civil en dos comunidades periféricas de Colombia", Desafíos vol. 30, n. ${ }^{\circ} 1$ (2018).

9 Vicenç Fisas, Negociar la paz con las FARC. Una experiencia innovadora (Barcelona: Icaria / Más Madera, 2017).

10 Mauricio García-Durán, S.J., Movimiento por la paz en Colombia. 1978-2003 (Bogotá: UNDP / Cinep / Colciencias, 2006).

11 Como pueblos indígenas y afrodescendientes, comunidades campesinas, mujeres, jóvenes, maestros y víctimas, entre otros.

12 John Paul Lederach, “¿Quién media en los países en desarrollo?”, Resolución de conflictos. Notes vol. 6, n. ${ }^{\circ} 4$ (1989): 82, 83.

13 Christopher Mitchel y Sara Ramírez, "Local Peace Communities in Colombia: An Initial Comparison of Three Cases", en Colombia: Building Peace in a Time of War, ed. Virginia M. Bouvier (Washington, D. C.: United States Institute of Peace Press, 2009), 245-270.

14 Esperanza Hernández Delgado, Intervenir antes que anochezca. Mediaciones, intermediaciones y diplomacias noviolentas de base social en el conflicto armado colombiano (Bucaramanga: Universidad Autónoma de Bucaramanga, 2012).

15 Marco Gerardo Monroy Cabra, Métodos alternativos de solución de conflictos (México: Oxford University Press, 1997). 
el caso de la antigua China, dado que allí la mediación representaba el principal mecanismo para solucionar diferencias. Confucio afirmaba que la mejor forma de preservar la armonía natural en las relaciones humanas y resolver disputas era mediante la persuasión moral y los acuerdos, y no a través de la fuerza y la coacción ${ }^{16}$. La intervención de terceros para resolver conflictos también ha representado una práctica ancestral de pueblos indígenas y comunidades negras ${ }^{17}$. Asimismo se ha hecho visible en la regulación de conflictos generada desde leyes o políticas públicas, siendo el caso por ejemplo de la que surgió a partir de la Ley de las XII tablas en la antigua Roma, y de los avenidores o amigables componedores del siglo XII, en Portugal. De igual manera, ha representado un mecanismo al que han acudido de manera recurrente los Estados para resolver conflictos armados de carácter internacional ${ }^{18}$.

La mediación y otros mecanismos alternativos de resolución pacífica de conflictos se fue generalizando y profesionalizando en la historia reciente de la humanidad, y con mayor énfasis en las décadas de los setenta y ochenta del siglo $X X^{19}$, muy especialmente en EE. UU., Inglaterra y Francia.

La mediación es considerada como la más exitosa de las técnicas alternativas de resolución de conflictos ${ }^{20}$. Esta afirmación se soporta en diversos hechos y en factores de la propia naturaleza de esta modalidad de intervención de terceros: su aplicación se ha extendido a conflictos de ámbitos privados y públicos, desde la familia y la escuela hasta los conflictos armados ${ }^{21}$; el ochenta por ciento de conflictos sometidos a mediación han terminado en acuerdos, según hallazgos de investigación ${ }^{22}$; y por permitir la participación de las partes en la búsqueda de soluciones del conflicto, otorgándoles voz, facilitando que se reconozcan y posibilitando que legitimen su actuación y las decisiones que adoptan.

Son diversos los significados atribuidos a la mediación, aunque no existe en la actualidad una definición universalmente aceptada sobre la misma. En forma generalizada coinciden algunos analistas al considerarla como una técnica de gestión, conducción, transformación y resolución de conflictos ${ }^{23}$; y otros, desde una mirada más amplia, la identifican como mecanismo de construcción de paz $^{24}$.

16 Jay Folberg y Alison Taylor, Mediación. Resolución de conflictos sin litigio (México: Limusa / Grupo Noriega Editores, 1996).

17 Hernández Delgado, Intervenir.

18 Esperanza Hernández Delgado, "Aproximación teórica a los significados de la mediación en conflictos armados", Reflexión Política, vol. 12, n. ${ }^{\circ} 24$ (2010).

19 Vicenç Fisas, Procesos de paz y negociación en conflictos armados (Barcelona: Paidós, 2004); Marinés Suares, Mediación. Conducción de disputas, comunicación y técnicas (México: Paidós / SAICF, 1996).

20 Suares, Mediación.

21 Beatriz Martínez de Murguía, Mediación y resolución de conflictos. Una guía introductoria (México: Paidós, 1999).

22 Kenneth Kressel y Dean G. Pruitt, Mediation Research: The Process and Effectiveness of Third-Party Intervention (San Francisco: Wiley, 1989).

23 John Paul Lederach, Enredos, pleitos y problemas. Una guía práctica para ayudar a resolver conflictos (Akron: Comité Central Menonita, 1985); Suares, Mediación.

24 Vicenç Fisas, Cultura de paz y gestión de conflictos (Barcelona: Icaria / Unesco, 1998); Fisas, Procesos de paz); John Paul, Lederach, La imaginación moral. El arte y el alma de construir la paz (Bogotá: Editorial Norma, 2008). 
La mediación no es solo una construcción teórica, es al mismo tiempo una práctica social. En el marco de la misma se pueden restablecer vínculos entre las partes en conflicto y romper círculos viciosos de conflicto y violencia. A su vez, las partes involucradas pueden ver los conflictos desde otra perspectiva, que no solo es útil a su presente sino a su futuro. Además, favorece una "cultura de vinculación" en su significación de reparación, restablecimiento y reforzamiento de vínculos consigo mismo, con el prójimo, con el entorno material, social y ecológico. La mediación es conocida como "la tercera vía" en la solución de conflictos, ya que en ella, quienes están en conflicto, se encuentran a través de un mediador que les ayuda a comunicarse para que puedan encontrar una solución mutuamente satisfactoria en el conflicto que los vincula ${ }^{25}$. En este artículo se entiende la mediación, en términos generales, en la significación que le atribuye el concepto que se relaciona a continuación:

La mediación es la intervención de un tercero aceptable, imparcial y neutral, carente de poder de decisión, en una disputa o negociación, con el fin de ayudar a las partes en conflicto a llegar voluntariamente a un acuerdo propio y mutuamente aceptable alrededor de los puntos en disputa. ${ }^{26}$

\section{Sobre la mediación en conflictos armados}

La mediación en conflictos armados es reciente y por ello novedosa ${ }^{27}$. Hasta el momento no se cuenta con un concepto único sobre esta modalidad de mediación. Existen comprensiones clásicas o tradicionales y otras más amplias y jóvenes. En las primeras, la mediación se concibe como la intervención de un tercero en un proceso formal de negociación directa cara a cara, para ayudar a las partes a encontrar soluciones mutuamente satisfactorias para resolver su conflicto $^{28}$. En esta concepción, el mediador es generalmente un experto, externo o ajeno al conflicto, que cuenta con un margen de disponibilidad para actuar a modo propio, que ha sido aceptado previamente por las partes y goza de prestigio ${ }^{29}$.

Dentro de las comprensiones más amplias se identifican dos enfoques. El primero, que considera la mediación como la intervención de diversos terceros con distintos roles, en las etapas de pre negociación, negociación y pos negociación de un proceso de $\mathrm{paz}^{30}$. El segundo, que la define como la intervención

25 Hernández Delgado, Intervenir.

26 Christopher Moore, El Proceso de Mediación. Métodos prácticos para la resolución de conflictos (Buenos Aires: Granica, 1995).

27 Laura Wills Otero, La mediación como herramienta parar la resolución de conflictos armados internos (Bogotá: Alfaomega, 2003 ), 4.

28 Moore, El proceso de mediación.

29 Esperanza Hernández Delgado, "Modelos propios de mediación de pueblos y comunidades en Colombia", Perpektive mediation, vol. $6,{ }^{\circ}{ }^{\circ}$ (2019).

30 Fisas, Procesos de paz. 
de terceros involucrados en el conflicto, que por esta condición son terceros de confianza, es decir, conocedores del conflicto, de los actores del mismo y de su accionar, y que gozan de autoridad y credibilidad ${ }^{31}$. La intencionalidad de este tipo de mediación es ayudar a encontrar alternativas de solución relacionadas con la protección de mínimos vitales violentados o amenazados en el marco de conflictos armados: la vida, las culturas, los territorios y la autonomía o autodeterminación. En este caso, la mediación la realiza un colectivo, que reúne unas características especiales, y que ha recibido un mandato comunitario para mediar ${ }^{32}$.

Estas tendencias, al definir la mediación en conflictos armados, hacen visible la complejidad de esta mediación, que también es propia de los conflictos que intenta resolver o transformar. De igual manera, evidencian los plurales perfiles de quienes median, los escenarios en los que actúan y las intencionalidades presentes en esta mediación.

Se destaca la incidencia de factores propios de los conflictos armados en esta mediación. Dentro de los mismos, la especificidad de cada uno de estos conflictos, su carácter dinámico y cambiante, la complejidad de los contextos en los que surgen, la imposibilidad de replicar experiencias y aprendizajes de manera generalizada, y que solo las partes involucradas tienen el poder para resolver estos conflictos, independientemente de la labor de quienes median ${ }^{33}$.

La mediación en conflictos armados cuenta con un significativo desarrollo teórico. No obstante, es necesario avanzar más, desde ejercicios aplicados de investigación para la paz, que ofrezcan elementos teóricos y prácticos que soporten aspectos relevantes sobre la misma. En este sentido, cobra importancia el análisis de casos o experiencias, el perfil de los terceros mediadores, sus alcances y las lecciones aprendidas sobre esta mediación. En Colombia son incipientes los esfuerzos investigativos sobre mediación en conflictos armados.

Estudios de caso como la experiencia campesina de mediación de la ATCC, objeto de este artículo, contribuyen a este propósito de ofrecer elementos que permitan avanzar en la comprensión y caracterización de la mediación en conflictos armados internos. Ellos enseñan que, en este tipo de conflictos, la mediación exige modelos y perfiles especiales de mediación. De igual manera, que en su ejercicio se compromete la vida y están muy presentes la paciencia, la humildad y el compromiso de quienes median ${ }^{34}$. Además, que como dice Lederach: "la necesidad de reconstruir el tejido social de relaciones desgarradas por décadas y generaciones de odio continúa siendo un reto importante (...) ¿Cómo trascendemos los ciclos de violencia?" 35 .

\footnotetext{
31 Lederach, “¿Quién media...?”, 82, 83.

32 Hernández Delgado, “Modelos propios de mediación”, 234-239.

33 Hernández Delgado, Intervenir, 487.

34 Ibíd.

35 Lederach, La imaginación moral.
} 


\section{La Asociación de Trabajadores Campesinos del Carare}

En Colombia, mucho antes de la expedición de la Constitución Política de 1991, que consagró el derecho y el deber de la paz, pueblos indígenas y afrodescendientes, y comunidades campesinas, mediaban en el conflicto armado colombiano ${ }^{36}$.

La Asociación de Trabajadores Campesinos del Carare, en adelante ATCC, es un proceso con una importante trayectoria en construcción de paz. Se destacan dentro de sus principales rasgos: su larga duración y la perfectible consolidación que ha alcanzado; sus dimensiones como resistencia noviolenta y mediación en el conflicto armado, los logros que ha alcanzado en sus 32 años de existencia, y el reconocimiento que ha obtenido, especialmente el premio Nobel Alternativo de Paz que les otorgaron en 1991.

Esta experiencia campesina surgió en 1987, como ejercicio de resistencia civil frente al conflicto armado y todos sus actores. A partir de esta postura, desarrollaron una labor de mediación en dicho conflicto, que se ha mantenido hasta la actualidad. La integran aproximadamente doce mil campesinos, treinta $\mathrm{y}$ tres veredas de seis municipios ${ }^{37}$ que colindan con el río Carare o Minero, en el Magdalena Medio santandereano, y que constituye su área de influencia ${ }^{38}$.

En 1987, los campesinos que generaron la ATCC y se organizaron en ella no sabían de pacifismo, noviolencia, ni de mecanismos de resolución de conflictos; muchos de ellos apenas sabían leer y escribir y vivían inmersos, desde 1975, en una realidad de violencia extrema: eran víctimas de un conflicto armado que se expresaba en dimensiones de barbarie y terror ${ }^{39}$. Sin embargo, en forma extraordinaria, desde sus capacidades y potencialidades para construir la paz crearon una propuesta auténtica, creativa y con alcances reales y perfectibles, que ellos identifican como mediación en ese conflicto armado.

Entre 1975 y 1987, la población campesina asentada en el territorio, que después integraría el área de influencia de la ATCC, fue objeto indiscriminado del accionar degradado de todos los actores del conflicto armado, por entonces escalado como consecuencia de la confrontación y el fuego cruzado ${ }^{40}$. En un primer momento, que se extiende hasta 1982, enfrentó al Ejército con la insurgencia de las FARC, y en una segunda fase, que va desde 1982 hasta 1987, al Ejército y los Paramilitares contra las FARC. Durante este largo periodo, el conflicto

36 Hernández Delgado, Intervenir.

37 Cimitarra, Landázury, Bolívar, Sucre, La Belleza y el Peñón.

38 Esperanza Hernández Delgado y Claudia Patricia Roa Monsalve, "Civil Resistance and Peacebuilding: The Experience of the Peasant Worker Association of the Carare River", en Civil Resistance and Violent Conflict in Latin America. Mobilizing for Rights, eds. Cécile Mouly y Esperanza Hernández Delgado (Switzerland: Palgrave Macmillan, 2019), 137-156.

39 Hernández Delgado, Resistencia civil, artesana, 316-326; Pedro Valenzuela Gruesso, "Construcción de paz desde la base: la experiencia de la Asociación de Trabajadores Campesinos del Carare (ATCC)", en Las prácticas de resolución de conflictos en América Latina, coord. Manuel Ernesto Salamanca (Bilbao: Universidad de Deusto, 2008), 119-136; Centro Nacional de Memoria Histórica, El orden desarmado. La resistencia de la Asociación de Trabajadores Campesinos del Carare (ATCC) (Bogotá: Taurus, 2011).

40 Esperanza Hernández Delgado y Claudia Patricia Roa Mendoza, "Resistencia civil al conflicto armado interno colombiano. El caso de la ATCC”, en Resistencias noviolentas en América Latina. Experiencias en Brasil, Colombia y México, coords. Esperanza Hernández Delgado y Cécile Mouly (Bogotá: FLACSO Ecuador / Universidad de La Salle, 2020), 125-152. 
en mención cobró aproximadamente quinientas víctimas directas, sin contar dentro de este estimativo a los familiares de las mismas y las comunidades de las que hacían parte; y evidenció dimensiones de barbarie y terror. En este contexto, la desaparición forzada, la tortura, el tiro de gracia, el asesinato selectivo, el bombardeo, el desplazamiento forzado, la mutilación de los cuerpos y segar la vida, materializaron las violaciones de Derechos Humanos y las infracciones al Derecho Internacional Humanitario perpetradas en contra de esta población. Ellas quedaron por siempre registradas en su memoria y generaron heridas que aún no han podido cicatrizar ${ }^{41}$.

Por esos años, en muchos momentos el río Carare perdió su condición para convertirse en testigo mudo de la barbarie, depositario de los cuerpos mutilados y sin vida, y dejó de transportar embarcaciones, productos agrícolas y madera, para arrastrar cadáveres - que era prohibido recoger-, algunas veces hasta quince en un día, que endurecían el miedo y daban cuenta del horror ${ }^{42}$.

La chispa detonante del conflicto fue un ultimátum que les dio un miembro del Ejército a los campesinos del Carare. Al cierre del periodo mencionado de violencia y escalamiento del conflicto armado, el 17 de febrero de 1987 se presentó en la India ${ }^{43}$ un capitán del Ejército en compañía de algunos comandantes de los paramilitares, como el Mojao, convocó a los campesinos a un sitio público y les manifestó que les daba el plazo perentorio de diez días para que decidieran entre cuatro alternativas, todas ellas inmersas en la violencia: vincularse a la insurgencia, unirse a los paramilitares, desplazarse del territorio o permanecer en él y morir en las lógicas del conflicto armado ${ }^{44}$.

En el contexto descrito, surgió la experiencia de resistencia civil de la ATCC, y a partir de la misma, la de mediación en el conflicto armado interno. Es necesario destacar que esta intervención de la ATCC en el conflicto en mención no encontró su origen en una teoría académica o en influencias externas. Surgió como iniciativa de estos campesinos y en su desarrollo se convirtió en proceso. Por ese motivo tiene un carácter propio y auténtico. Se identifican como causas generadoras de la misma las necesidades impuestas por la expresión del conflicto armado en su territorio, la opción de los campesinos por el ejercicio de resistencia civil frente a esta modalidad de violencia y todos sus actores; el liderazgo de quienes orientaron a la comunidad y contribuyeron a su opción por la resistencia noviolenta y la práctica de mediación, y en el poder pacífico transformador de las comunidades que han integrado esta experiencia campesina ${ }^{45}$.

Los campesinos de la ATCC comprenden la mediación como un proceso inacabado, que se construye en el día a día, cuya intencionalidad está directamente asociada con la defensa de la vida, de la autonomía y de los derechos al

41 Hernández Delgado y Roa Mendoza, "Resistencia civil”, 135.

42 Hernández Delgado, Resistencia civil, artesana, 323-326.

43 La India es un corregimiento del municipio de Landázury y el centro poblacional más grande del área de influencia de la ATCC.

44 Alejandro García, Hijos de la violencia. Campesinos de Colombia sobreviven a "golpes" de paz (Madrid: Los Libros de la Catarata, 1996); Hernández Delgado, Resistencia civil, artesana; Valenzuela Gruesso, "Construcción de paz", 119-136; Centro Nacional de Memoria Histórica, El orden desarmado.

45 Hernández Delgado, Intervenir, 208, 213, 217, 218. 
trabajo y a la paz. Se media desde un modelo y unas estrategias propias y con todos los actores del conflicto armado ${ }^{46}$. En sus propias palabras:

\begin{abstract}
Mediar en el conflicto armado significa respeto por la vida y por la autonomía comunitaria, humanizar personas violentas, y solución propia de los problemas. También conocer el poder transformador que tiene el diálogo abierto y el consenso, crear nuestro propio proyecto de vida, ser un ejemplo de que sí hay salidas al conflicto cuando hay unión y superando el miedo, romper con la indiferencia, hacer trabajo conjunto sin importar el credo, la cultura o el pensamiento. ${ }^{47}$

Si le quitamos la mediación a la ATCC, yo creo que perderíamos la razón de ser porque la mediación es la que ha permitido que muchas cosas en el área de influencia se logren y que la gente pueda convivir en paz, tranquilamente. Que algunas personas, a pesar de que hayan tenido algún problema, no se les ajusticie por eso que hicieron, sino que puedan permanecer en el territorio, ser perdonados, rectificarse, que haya entendimiento, y que también la región se siga desarrollando. ${ }^{48}$
\end{abstract}

Para la ATCC, mediar es un proceso, generado y validado por la historia de estas comunidades campesinas y por su pensamiento político. También, un mecanismo de gestión pacífica de los conflictos que se materializa en la palabra, el diálogo y los acuerdos. Un ejercicio difícil, que ha implicado valor, asumir altos riesgos, como la probabilidad de perder la vida o ser estigmatizado, y que ha comprometido plurales esfuerzos. Desde buscar contacto con quienes les permitan contactar a los actores del conflicto armado para "interlocutar" con ellos, hasta las largas travesías que han tenido que realizar para encontrarse con ellos, muchas veces caminando y durmiendo por varios días bajo el ardiente sol o la persistente lluvia ${ }^{49}$.

En consideración de quienes han generado y dinamizado esta experiencia, y desde hallazgos de investigación para la paz, es posible afirmar que este proceso de mediación ha sido exitoso. Soportan esta afirmación sus diversos e inimaginables logros, su práctica generalizada y reiterada, la cultura de la mediación que ha generado en el interior de sus comunidades, su larga duración, y porque desde sus orígenes ha hecho ruptura perfectible en el conflicto armado, sus lógicas y su intensidad, alcanzando incluso largos periodos ${ }^{50}$ en los que no se registraron muertes violentas por su causa en el área de influencia de la ATCC ${ }^{51}$.

Los logros de esta experiencia de mediación han sido diversos, significativos y palpables. Han protegido vidas, culturas y territorios en medio del escalamiento del conflicto armado, han prevenido el desplazamiento forzado, y por momentos han disminuido su intensidad. A su vez, han fortalecido la unidad y los procesos comunitarios, han evidenciado los alcances de métodos más inteli-

\footnotetext{
46 Ibíd.

47 Entrevista a Quiroga Rueda, Donaldo, La India, 7 de julio de 2010.

48 Entrevista a Hernández, Mauricio, La India, 10 de julio de 2010.

49 Hernández Delgado, Intervenir.

50 Como el comprendido entre 1991 y 1999.

51 Hernández Delgado, Intervenir.
} 
gentes y menos costosos, como los noviolentos en la resolución de conflictos, y han transformado la realidad.

\section{Modelo, método y estrategias}

El método y las estrategias empleadas por la ATCC para mediar en el conflicto armado han sido auténticos, inteligentes, sencillos y, a la vez, extraordinarios. A su vez, han sido probados a lo largo de un periodo que supera tres décadas y han evidenciado su eficacia.

Desde los estudios de paz, el método utilizado por la ATCC para mediar en el conflicto armado puede identificarse como el de la Noviolencia, en el que el valor de la vida, en su comprensión más amplia, representa la esencia, el fundamento y la intencionalidad del ejercicio de mediación. A su vez, privilegia el diálogo y el entendimiento como mecanismos para resolver los conflictos generados por el impacto del conflicto armado en las comunidades campesinas. Además, se destaca la percepción del adversario dentro del mismo, pues estos campesinos asumen a los actores del conflicto armado, no como sus enemigos, sino como personas que han tomado opciones y métodos distintos a los de ellos, que incluso les han causado daño; pero a quienes les reconocen la condición de seres humanos, susceptibles de cambio. Desde esa perspectiva, la mediación también busca transformar a estos actores ${ }^{52}$. En algunos casos han mediado para facilitar su desvinculación del movimiento armado o, cuando han asumido la condición de excombatientes, para posibilitar su reconciliación con las comunidades y con excombatientes de otros grupos armados ${ }^{53}$.

El modelo de mediación de la ATCC tiene características propias ${ }^{54}$. Ellas se relacionan a continuación:

- La mediación es un proceso. Para los campesinos que integran la ATCC, la mediación es un proceso inacabado y perfectible. Por consiguiente, no se agota en sesiones. Además está estrechamente vinculado a la protección de la vida y de otros mínimos vitales, factor que explica su carácter procesual e inacabado.

- Mediación comunitaria. Esta mediación la realiza un colectivo integrado por la junta directiva de la ATCC, los delegados de las veredas o la comisión de conciliadores, según el caso, quienes por sus condiciones y experiencia han sido elegidos para dicha labor. Se destaca que constituye una prohibición asumir esta labor de forma individual.

- Mediación con mandato comunitario. Quienes median no lo hacen a título personal, sino en cumplimiento de un mandato de sus comunidades o de la asamblea comunitaria de la ATCC. De igual manera, rinden cuentas de su ejercicio a las comunidades y sus espacios deliberativos y por lo tanto

\footnotetext{
52 Ibíd.

53 Cécile Mouly, Esperanza Hernández Delgado y Jaime Giménez, "Experiencias de reintegración social de excombatientes en comunidades de paz en Colombia”, Análisis político, vol. 32, n. 95 (2019).

54 Hernández Delgado, Intervenir.
} 
no se pueden extralimitar en sus funciones. Este mandato comunitario es el que da poder a quienes median y los colocan en posición de equilibrio frente a los actores armados.

- El perfil de quienes median. Quienes median en la ATCC deben tener unas condiciones especiales de carácter personal, organizativo y del ámbito de resolución pacífica de los conflictos. Dentro de las condiciones personales se destacan: el amor a la vida, la sencillez, la prudencia, la seriedad, la flexibilidad y gozar de reconocimiento dentro de su comunidad, como persona correcta, confiable y sin tacha. Respecto de las condiciones organizativas: su trayectoria en la organización y el conocimiento de la postura política de la organización frente al conflicto armado. En cuanto al campo de la resolución pacífica de los conflictos: contar con facilidad de expresión y comunicación, reconocimiento comunitario de su capacidad para resolver problemas y diferencias, conocimiento profundo del conflicto armado, sus actores y su accionar, y contar con experiencia en mediación. Se destaca que en este modelo la formación académica o la experticia académica no representan una exigencia para poder mediar.

- La intencionalidad de la mediación. Como ya se había manifestado antes, la finalidad es proteger mínimos vitales, afectados o amenazados por el conflicto armado. Entre estos: la vida en su consideración más amplia, es decir, no solo la vida humana, sino la de otras especies y la de la naturaleza, las culturas, los territorios, la autonomía o autodeterminación, y derechos fundamentales como los del trabajo y la paz. Esta mediación no tiene la finalidad de resolver pacíficamente el conflicto armado interno de Colombia, y carece de condiciones para ello. En este sentido, aboga por su resolución pacífica y solo media para encontrar alternativas de solución frente a la conflictividad generada entre los actores del mismo y las comunidades.

- Las estrategias empleadas. Son diversas, propias, inteligentes y aprovechan los recursos disponibles en el interior de sus comunidades y contextos. Se identifican entre ellas: a. Los diálogos públicos y de cara a las comunidades. En muchas ocasiones, las comunidades se desplazaron por el río acompañando a sus directivos, encargados de la mediación, hasta el lugar convenido para el encuentro, como muestra de respaldo y apoyo comunitario. En otras ocasiones, cuando los mediadores iban solos, grababan los diálogos y al regresar a los cascos urbanos, los retransmitían en sitios públicos mediante parlantes de gran potencia para que pudieran ser conocidos por todos; $b$. Manifestar a cada actor armado que su postura frente a ellos era igual a la que sostenían frente a los demás actores armados. Este criterio evidenciaba imparcialidad y ayudaba a generar confianza; c. Establecer como regla, con cada actor armado, que lo acordado con ellos sería dado a conocer a los otros actores del conflicto armado; d. Contar con el respaldo de sus comunidades que, como se mencionó antes, les otorgaba poder y permitía un mayor equilibrio en la relación de poder 
frente a los actores armados; e. Colocar vallas enormes a la entrada de las veredas con la frase: "Conmigo no cuente para la guerra"; e. Iniciar cada sesión de diálogo pidiéndoles a los actores armados dejar a un lado sus armas por un momento para disponerse a la oración como práctica de fortalecimiento espiritual; f. Humanizar al actor armado reconociendo su dignidad y tocando su corazón; g. Lograr acuerdos históricos firmados por los actores armados, que sentaron la base fundamental para protegerlos en el futuro y frente a nuevos comandantes y otras dinámicas del conflicto armado.

- La planeación o preparación de la mediación. Los mediadores de la ATCC preparan cuidadosamente su ejercicio de mediación, desde el contacto inicial hasta el desarrollo de las sesiones. Ellos estudian las características de sus interlocutores, preparan las intervenciones, la agenda de diálogo y los argumentos que expondrán, tratando de no dejar nada al azar.

- Elección de quienes median. Los mediadores son elegidos por las comunidades, otorgándoles, a su vez, un mandato para mediar.

- Calidad de terceros. Quienes median se consideran terceros entre los actores armados y sus comunidades. Se sienten con derecho a mediar en su condición de afectados directos por el conflicto armado interno y por la autoridad que les otorga conocer de primera mano la expresión de este conflicto, sus actores y su accionar. Por estas mismas razones no piden autorización a ningún actor armado para mediar.

\section{CONCLUSIONES}

- Colombia cuenta con un valioso, creciente e insuficientemente explorado universo de escenarios de construcción de paz. Por este motivo, no corresponde a su realidad percibirla solo por las violencias que se expresan en su territorio.

- La mediación en los conflictos armados representa una modalidad novedosa y en construcción, compleja como los conflictos que intenta resolver o transformar; pero valiosa, necesaria y muchas veces la única y más idónea vía para intervenir en conflictos armados prolongados y arraigados.

- No existe un concepto universalmente aceptado sobre esta modalidad de mediación. Se cuenta con un desarrollo teórico importante, pero es necesario avanzar en ejercicios aplicados de investigación para la paz, que ofrezcan elementos teóricos y prácticos, relacionados con experiencias, perfiles de mediadores, métodos, logros y lecciones aprendidas.

- Las experiencias comunitarias de mediación en conflictos armados, como la ATCC, representan un mecanismo valioso de resolución de la conflictividad generada por los actores de estos conflictos con comunidades que reciben su múltiple impacto. 
- La intervención de la ATCC en el conflicto mencionado representa una experiencia auténtica, dado que emerge de los campesinos que la generaron y quienes, a su vez, adoptaron un método noviolento y crearon un modelo genuino y unas estrategias propias.

- La noviolencia es su método, aunque estos campesinos carecían de una formación en Estudios de paz, ni conocían la figura de Gandhi cuando generaron esta experiencia. En este sentido, la protección de la vida está en el origen y la finalidad de esta mediación comunitaria. A su vez, se materializa en diálogos y acuerdos; y humaniza al adversario, a quien no perciben como enemigo sino como un ser humano que ha tomado una opción de vida y de lucha distinta a la de la ATCC, que incluso les ha causado daño, pero que tiene capacidad para cambiar.

- Es una experiencia exitosa por sus significativos logros, su práctica generalizada y reiterada, su larga duración, por generar una cultura de la mediación dentro de sus comunidades, y porque ha hecho ruptura en las lógicas del conflicto armado, empoderando a las comunidades e incidiendo en la resolución pacífica de la conflictividad generada por este conflicto.

- Esta experiencia enseña la importancia de los mediadores involucrados en los conflictos que se busca mediar, en su condición de víctimas de los mismos. Su conocimiento y su experiencia los convierte en mediadores autorizados.

- El modelo de mediación de la ATCC posibilita la participación comunitaria, factor que la fortalece como proceso y la legitima. A su vez, les otorga poder a quienes median y los sitúa en un punto de mayor equilibrio frente a los actores armados.

- Al poner en diálogo el modelo de mediación tradicional en conflictos armados con el generado y desarrollado por la ATCC, se hace evidente la necesidad de incorporar nuevos elementos teóricos y prácticos sobre esta modalidad de mediación. Dentro de los mismos, el perfil de los mediadores, su naturaleza interna o involucrada en los conflictos, las modalidades de esta mediación, los métodos y estrategias aplicadas y los logros alcanzados.

\section{REFERENCIAS}

Centro Nacional de Memoria Histórica. El orden desarmado. La resistencia de la Asociación de Trabajadores Campesinos del Carare (ATCC). Bogotá: Taurus, 2011.

Fisas, Vicenç. Cultura de paz y gestión de conflictos. Barcelona: Icaria / Unesco, 1998.

Fisas, Vicenç. Procesos de paz y negociación en conflictos armados. Barcelona: Paidós, 2004.

Fisas, Vicenç. Negociar la paz con las FARC. Una experiencia innovadora. Barcelona: Icaria / Más Madera, 2017.

Folberg, Jay y Alison Taylor. Mediación. Resolución de conflictos sin litigio. México: Limusa / 
Grupo Noriega Editores, 1996.

Galtung, Johan. Investigaciones teóricas. Sociedad y culturas contemporáneas. Madrid: Tecnos, 1995. García, Alejandro. Hijos de la violencia. Campesinos de Colombia sobreviven a "golpes" de paz. Madrid: Los Libros de la Catarata, 1996.

García-Durán, Mauricio, S. J. Movimiento por la paz en Colombia. 1978-2003. Bogotá: UNDP / Cinep / Colciencias, 2006.

Hernández Delgado, Esperanza. Resistencia civil, artesana de paz. Experiencias indígenas, afrodescendientes y campesinas. Bogotá: Editorial Pontificia Universidad Javeriana, 2004.

Hernández Delgado, Esperanza. “Aproximación teórica a los significados de la mediación en conflictos armados". Reflexión Política 12, n. ${ }^{\circ} 24$ (2010).

Hernández Delgado, Esperanza. Intervenir antes que anochezca. Mediaciones, intermediaciones y diplomacias noviolentas de base social en el conflicto armado colombiano. Bucaramanga: Universidad Autónoma de Bucaramanga, 2012.

Hernández Delgado, Esperanza. “Modelos propios de mediación de pueblos y comunidades en Colombia". Perpektive mediation 6, n. ${ }^{\circ} 4$ (2019): 234-239.

Hernández Delgado, Esperanza y Claudia Patricia Roa Monsalve. "Civil Resistance and Peacebuilding: The Experience of the Peasant Worker Association of the Carare River". En Civil Resistance and Violent Conflict in Latin America. Mobilizing for Rights, editado por Cécile Mouly y Esperanza Hernández Delgado. Switzerland: Palgrave Macmillan, 2019.

Hernández Delgado, Esperanza y Cécile Mouly, coordinadoras. Resistencias noviolentas en América Latina. Experiencias en Brasil, Colombia y México. Bogotá: FLACSO Ecuador / Universidad de La Salle, 2020.

Hernández Delgado, Esperanza y Claudia Patricia Roa Mendoza, "Resistencia civil al conflicto armado interno colombiano. El caso de la ATCC". En Resistencias noviolentas en América Latina. Experiencias en Brasil, Colombia y México, coordinado por Esperanza Hernández Delgado y Cécile Mouly. Bogotá: FLACSO Ecuador / Universidad de La Salle, 2020.

Kressel, Kenneth y Dean G. Pruitt. Mediation Research: The Process and Effectiveness of Third Party Intervention. San Francisco: Wiley, 1989.

Lederach, John Paul. Enredos, pleitos y problemas. Una guía práctica para ayudar a resolver conflictos. Akron: Comité Central Menonita, 1985.

Lederach, John Paul. “Quién media en los países en desarrollo?”. Resolución de conflictos Notes 6, n. ${ }^{\circ} 4(1989)$.

Lederach, John Paul. La imaginación moral. El arte y el alma de construir la paz. Bogotá: Editorial Norma, 2008.

Martínez de Murguía, Beatriz. Mediación y resolución de conflictos. Una guía introductoria. México: Paidós, 1999.

Monroy Cabra, Marco Gerardo. Métodos alternativos de solución de conflictos. México: Oxford University Press, 1997.

Mouly, Cécile y María Belén Garrido. “No a la guerra. Resistencia civil en dos comunidades periféricas de Colombia". Desafíos 30, n. ${ }^{\circ} 1$ (2018): 245-277.

Mouly, Cécile y Esperanza Hernández Delgado, editoras. Civil Resistance and Violent Conflict in Latin America. Mobilizing for Rights. Switzerland: Palgrave Macmillan, 2019.

Mouly, Cécile, Esperanza Hernández Delgado y Jaime Giménez. "Experiencias de reintegración social de excombatientes en comunidades de paz en Colombia". Análisis político 32, n. ${ }^{\circ} 95$ (2019): 3-22.

Mitchel, Christopher y Sara Ramírez. "Local Peace Communities in Colombia: An Initial Comparison of Three Cases". En Building Peace in a Time of War, editado por Virginia M. Bouvier. Washington, D. C.: United States Institute of Peace Press, 2009.

Moore, Christopher. El Proceso de Mediación. Métodos prácticos para la resolución de conflictos. Buenos Aires: Granica, 1995.

Muñoz, Francisco A., Joaquín Herrera, Beatriz Molina y Sebastián Sánchez. Investigación de la Paz y los Derechos Humanos desde Andalucía (Granada: Universidad de Granada, 2005). 
Salamanca, Manuel Ernesto, coordinador. Las prácticas de resolución de conflictos en América Latina. Bilbao: Universidad de Deusto, 2008.

Sánchez, Gonzalo y Ricardo Peñaranda, compiladores. Pasado y presente de la Violencia en Colombia. Bogotá: Cerec, 1986.

Suares, Marinés. Mediación. Conducción de disputas, comunicación y técnicas. México: Paidós / SAICF, 1996.

Valenzuela Gruesso, Pedro. "Construcción de paz desde la base: la experiencia de la Asociación de Trabajadores Campesinos del Carare (ATCC)". En Las prácticas de resolución de conflictos en América Latina, coordinado por Manuel Ernesto Salamanca. Bilbao: Universidad de Deusto, 2008.

Wills Otero, Laura. La mediación como herramienta parar la resolución de conflictos armados internos. Colombia: Alfaomega, 2003.

\section{Cómo citar:}

Hernández Delgado, Esperanza. “Mediación en conflictos armados. La experiencia de la Asociación de Trabajadores Campesinos del Carare (ATCC)". Revista Historia de la Educación Latinoamericana. 22 No. 35 (2020): 87-101 https://doi.org/10.19053/01227238.11919

(c) $(\Theta \Theta \Theta$ Esta obra está bajo una licencia Creative Commons. Reconocimiento-No Comercial-Sin Obra Derivada 2.5 Colombia. 
